\title{
EFFECTIVENESS OF PRE-TREATMENT METHOD TO HINDER REBAR CORROSION IN CONCRETE
}

\author{
N. Etteyeb ${ }^{a^{*}}$, M. Sanchez ${ }^{b}$, L. Dhouibi ${ }^{a}$, M. C. Alonso ${ }^{b}$, H. Takenouti ${ }^{c}$, E. Triki $^{\mathrm{a}}$ \\ a) - Unité de Recherche Corrosion et Protection des Métalliques, ENIT, B. P. 37, le Belvédère Tunis, 1002, Tunisia. \\ b) - Institute of Construction Science Eduardo Torroja (CSIC), Madrid 28033, Spain. \\ c) - UPR15 du CNRS, Université P. et M. Curie, 75252 Paris Cedex 05, France \\ * Corresponding author: E-mail address; nac_teyeb@yahoo.fr(Naceur ETTEYEB)
}

\begin{abstract}
The present work aims at evaluating the ability of phosphate pre-treatments applied on steel rebar's to hinder the corrosion reinforcements in a synthetic pore electrolyte contaminated by chloride ions and in mortar. The electrochemical behaviour of the pre-treated substrate was assessed by corrosion potential, polarization resistance and electrochemical impedance spectroscopy. The results have demonstrated that the treatment of the rebar by immersion in the $\mathrm{Na}_{3} \mathrm{PO}_{4}(0.5 \mathrm{M})$ solution favours the formation of a passive layer on the steel rebar surface, which is able to resist higher concentration of chlorides, up to $0.3 \mathrm{M}$, to initiate corrosion. The pretreatment also provides enhancement of corrosion protection of the steel rebar in mortar. The evolution of the impedance spectra with respect in function of chloride concentration are in a fairly good agreement with the results obtained by $E_{\text {corr }}$ and $j_{\text {corr }}$ measurements.
\end{abstract}

Keywords: Sodium Phosphate; Pre-treatment of rebars; Corrosion current density; EIS; Mortar. 